patients. In our cohort, patients with Anti-CarP antibodies presented higher tobacco consumption and poorer disease outcomes.

Table 1. Demographic and Clinical Features According to Anti-CarP Status

\begin{tabular}{|c|c|c|}
\hline & Anti-CarP positive $\mathrm{n}: 73$ & Anti-CarP negative $\mathrm{n}: 85$ \\
\hline Female & $52(71.2 \%)$ & $71(83.5 \%)$ \\
\hline Mean age at diagnosis (SD) & $53.6( \pm 11.9)$ & $53.8( \pm 14.4)$ \\
\hline Mean age at inclusion (SD) & $58.7( \pm 11.9)$ & $58.9( \pm 14.1)$ \\
\hline Extra-articular manifestations & $21(28.8 \%)$ & $15(17.6 \%)$ \\
\hline Disease duration (SD) & $5.1( \pm 2.7)$ & $5.0( \pm 2.7)$ \\
\hline Smoking history & $40(54.8 \%)$ & $32(37.6 \%)$ * \\
\hline - Previous and/or current & $18(24.7 \%)$ & $10(11.8 \%)$ * \\
\hline \multicolumn{3}{|l|}{ - Current } \\
\hline RA family history & $12(16.4 \%)$ & $10(11.8 \%)$ \\
\hline BMI & $27.5( \pm 4.5)$ & $27.1( \pm 5)$ \\
\hline Disease presentation at initiation (\%) & $15(20.5 \%)$ & $14(16.5 \%)$ \\
\hline - Palindromic rheumatism & $7(9.6 \%)$ & $6(7.1 \%)$ \\
\hline - Inflammatory arthralgia & $4(5.5 \%)$ & $1(1.2 \%)$ \\
\hline - Pseudopolymyalgia & $47(64.4 \%)$ & $64(75.3 \%)$ \\
\hline \multicolumn{3}{|l|}{ - Polyarticular arthritis } \\
\hline Mean DAS28 (SD): & $3.0( \pm 1.3)$ & $2.8( \pm 1.2)$ \\
\hline - Remission/Low & $65.8 \%$ & $68.2 \%$ \\
\hline Mean DAS28 PCR (SD); & $2.7( \pm 1.2)$ & $2.4( \pm 1.1)$ \\
\hline - Remission/Low & $72.6 \%$ & $80.0 \%$ \\
\hline Mean CDAI (SD); & $9.2( \pm 8.2)$ & $7.2( \pm 6.5)$ \\
\hline - Remission/Low & $71.2 \%$ & $80.0 \%$ \\
\hline Mean SDAI (SD); & $10.2( \pm 8.6)$ & $7.8( \pm 6.9)$ \\
\hline - Remission/Low & $68.5 \%$ & $77.6 \%$ \\
\hline Mean RAPID3 (SD): & $10.2( \pm 8.6)$ & $7.8( \pm 6.9)$ \\
\hline - Remission/Low & $47.2 \%$ & $48.2 \%$ \\
\hline Mean HAQ (SD) & $0.45( \pm 0.52)$ & $0.29( \pm 0.39)$ \\
\hline Poor $\mathrm{HAQ}(>1)$ & $17(23.3 \%)$ & $7(8.3 \%)^{* *}$ \\
\hline Pain Analogue Scale mm (SD) & $27.6( \pm 29.8)$ & $20.6( \pm 22.7)$ \\
\hline Treatment: & $44(61.1 \%)$ & $49(57.6 \%)$ \\
\hline - Glucocorticoids & $63(86.3 \%)$ & $71(83.5 \%)$ \\
\hline - cDMARDs & $48(65.8 \%)$ & $56(65.9 \%)$ \\
\hline - MTX & $7(9.6 \%)$ & $12(14.1 \%)$ \\
\hline$\cdot \mathrm{HCQ}$ & $14(19.2 \%)$ & $14(16.5 \%)$ \\
\hline$\cdot \operatorname{LEF}$ & $17(23.3 \%)$ & $32(24.8 \%)$ \\
\hline \multicolumn{3}{|l|}{ • bDMARDs } \\
\hline Erosive disease & $37(50.7 \%)$ & $46(54.8 \%)$ \\
\hline Modified Larsen Score & $23.6( \pm 15.7)$ & $15.7( \pm 12.6)^{* *}$ \\
\hline
\end{tabular}

Disclosure of Interests: Raul Castellanos-Moreira Speakers bureau: For Lilly and Merk Sharp and Dohme, Sebastian C Rodriguez-García: None declared, Virginia Ruiz: None declared, Oscar Camacho: None declared, Julio Ramirez: None declared, Andrea Cuervo: None declared, Cristina Garcia-Moreno: None declared, Rosa Morla: None declared, José Gomez Puerta Speakers bureau: BMS, Pfizer, Amgen, Juan D. Cañete: None declared, Isabel Haro: None declared, Raimón Sanmartí Speakers bureau: PFIZER, SANOFI, LILLY, MSD, UCB, NOVARTIS, JANSSEN

DOI: 10.1136/annrheumdis-2019-eular.6240

\section{THU0069 RHEUMATOID CACHEXIA ASSESSED BY BODY COMPOSITION IS ASSOCIATED WITH WORSE DISEASE IN RHEUMATOID ARTHRITIS PATIENTS WITH NORMAL BODY MASS INDEX}

Jian-Zi Lin, Lijuan Yang, Le-Feng Chen, LI Qian-Hua, MA Jianda, Yingqian Mo, Lie Dai. Sun Yat-Sen Memorial Hospital, Sun Yat-Sen University, Department of Rheumatology, Guangzhou, China

Background: Abnormal body composition (BC) has been reported in rheumatoid arthritis (RA) patients with normal body mass index (BMI). Rheumatoid cachexia (RC) was found in RA patients with a decrease in muscle mass and an increase or limited change in fat mass, resulting in no or limited changes in BMI. However, there is no consensus on the clinical criteria for its diagnosis, and the clinical significance of $\mathrm{RC}$ has not been well known until now.

Objectives: To investigate the characteristics of $B C$ in $R A$ patients with normal BMI and the association between RC and disease characteristics. Methods: Consecutive RA patients were recruited and clinical data including disease activity, function and radiographic assessment were collected. $\mathrm{BC}$ was assessed by bioelectric impedance analysis. $\mathrm{RC}$ was defined as those with concurrent overfat (body fat percentage $\geq 25 \%$ for men and $\geq 35 \%$ for women) and myopenia (appendicular skeletal muscle mass index $\leq 7.0 \mathrm{~kg} / \mathrm{m}^{2}$ in men and $\leq 5.7 \mathrm{~kg} / \mathrm{m}^{2}$ in women) in this study. Multivariate logistic regression analysis was performed to identify the association between disease characteristics and RC in RA patients with normal $\mathrm{BMI}$, following the step-forward selection rule that variables were included in the equation when the $P$ value was $<0.05$ or removed when the $P$ value was $>0.10$.

Results: 1. There were $516 \mathrm{RA}$ patients recruited, with $13.8 \% \mathrm{RC}$ as well as $17.4 \%$ underweight, $56.4 \%$ normal weight, $22.5 \%$ overweight and $3.7 \%$ obese respectively. Among 71 RA patients with RC, 73.2\% showed normal BMI, while $2.8 \%$ underweight, $22.5 \%$ overweight and $1.4 \%$ obese Among RA patients with normal BMI ( $n=291), 17.9 \%$ patients showed RC, $28.1 \%$ showed normal fat but myopenia, $1.4 \%$ showed overfat but non-myopenia, while $52.6 \%$ showed both normal fat and non-myopenia. 2. For RA patients with normal BMI, compared with those with both normal fat and non-myopenia, RA patients with RC were older with longer disease duration, higher disease activity indicators including 28TJC, PtGA PrGA, PainVAS, ESR, CRP, DAS28-CRP, SDAI and CDAI, higher functional indicators including HAQ-DI and rate of functional limitation, higher radiographic assessment including mTSS, JSN and JE subscores, higher rate of previous use of glucocorticosteroids $(75.0 \%$ vs. $52.3 \%)$, and higher prevalence of hypertension $(25.0 \%$ vs. $7.8 \%)$. Further compared with those with normal fat but myopenia, RA patients with RC showed the similar results with significantly longer disease duration, higher CRP HAQ-DI, mTSS, JSN subscore, JE subscore, and higher rate of previous use of glucocorticosteroids (all $P<0.0167$, bonferroni correction). 3. Multivariate logistic regression analysis showed that CRP $(O R=1.024,95 \% \mathrm{Cl}$ 1.009-1.040), mTSS (OR=1.017, 95\% Cl: 1.010-1.025), previous use of glucocorticosteroids $(O R=2.605,95 \% \mathrm{Cl}$ : 1.217-5.575), and suffering from hypertension (OR=3.462, 95\% Cl: 1.448-8.274) were positively associated with RC in RA patients with normal BMI.

Conclusion: Our data show rheumatoid cachexia is associated with worse disease including RA disease activity, functional limitation and radiographic joint damage, which imply that $\mathrm{RC}$ should be emphasized especially in RA patients with normal BMI.

Acknowledgement: This work was supported by National Natural Science Foundation of China (no. 81671612 and 81801606), Guangdong Natural Science Foundation (no. 2017A030313576, 2017A030310236 and 2018A030313541) and Guangdong Medical Scientific Research Foundation (no. A2017109).

Disclosure of Interests: None declared

DOI: 10.1136/annrheumdis-2019-eular.6477

\section{THU0070 WHAT IS THE ADDITIONAL VALUE OF MRI OF THE FOOT TO THE HAND IN UNDIFFERENTIATED ARTHRITIS TO PREDICT RHEUMATOID ARTHRITIS DEVELOPMENT?}

Yousra Dakkak ${ }^{1}$, Debbie Boeters ${ }^{1}$, Aleid Boer ${ }^{1}$, Monique Reijnierse ${ }^{2}$, Annette van der Helm - van Mil ${ }^{1,3} .{ }^{1}$ Leiden University Medical Center (LUMC), Rheumatology, Leiden, Netherlands; '2 Leiden University Medical Center (LUMC), Radiology, Leiden, Netherlands; ${ }^{3}$ Erasmus University Medical Center, Rheumatology, Rotterdam, Netherlands

Background: MRI-detected subclinical joint inflammation in hand-joints of patients with undifferentiated arthritis (UA) predicts progression to rheumatoid arthritis (RA). It is unknown if adding $M R I$ of the foot increases predictive accuracy compared to the hand alone.

Objectives: To assess whether MRI-detected inflammation of the foot is predictive for RA-development, and whether combining MRI-detected inflammation of the foot to that of the hand is of additional value.

Methods: 1.5T-contrast-enhanced MRI of unilateral foot (MTP-1-5), and hand (MCP-2-5 and wrist) was performed in 123 patients presenting with UA (not fulfilling 2010 RA-criteria) and scored for bone marrow edema (BME), synovitis and tenosynovitis. Symptom-free controls $(n=193)$ served as a reference for defining an abnormal MRI. Patients were followed for RA-development $\leq 1$-year, defined as fulfilling classification criteria or initiation of disease modifying anti-rheumatic drugs because of the expert opinion of RA. The added predictive value of foot-MRI to hand-MRI was evaluated.

Results: $52 \%$ developed RA. Foot tenosynovitis was predictive (OR 2.55, $95 \% \mathrm{Cl} 1.01-6.43$ ), independent of $\mathrm{BME}$ and synovitis (OR $3.29,95 \% \mathrm{Cl}$ 1.03-10.53), but not independent of CRP and number of swollen joints (OR 2.14, 95\% $\mathrm{Cl}$ 0.77-5.95). Hand tenosynovitis was also predictive independent of $\mathrm{BME}$ and synovitis (OR $3.99,95 \% \mathrm{Cl} 1.64-9.69)$ and independent of CRP and swollen joints (OR 2.36, 95\%Cl 1.04-5.38). Adding foot tenosynovitis to hand tenosynovitis changed sensitivity from $72 \%$ to $73 \%$, specificity from $59 \%$ to $54 \%$ and AUC from 0.66 to 0.64 , the net reclassification index was -3.5 .

Conclusion: MRI-detected tenosynovitis of the foot predicts progression to RA. However adding MRI of the foot does not improve predictive accuracy compared to $\mathrm{MRI}$ of the hand alone. In view of cost-reduction, performance of foot-MRI for prognostic purposes in UA can be omitted. 
Disclosure of Interests: Yousra Dakkak: None declared, Debbie Boeters: None declared, Aleid Boer: None declared, Monique Reijnierse Grant/ research support from: Funding from the Dutch Arthritis Foundation. The funding source had no role in the design and conduct of the study., Annette van der Helm - van Mil Grant/research support from: The research leading to these results has received funding from the European Research Council (ERC) under the European Union's Horizon 2020 research and innovation programme (Starting grant, agreement No 714312) and from the Dutch Arthritis Foundation.

The funding source had no role in the design and conduct of the study. DOI: 10.1136/annrheumdis-2019-eular.1698

\section{THU0071 THE COMBINATION OF RHEUMATOID FACTORS WITH ANTIBODY SYSTEMS TARGETING CITRULLINATED, CARBAMYLATED AND PEPTIDYL ARGININE DEIMINASE AUTOANTIGENS DISTINGUISHES RHEUMATOID ARTHRITIS}

Thierry Dervieux ${ }^{1}$, John Conklin ${ }^{1}$, Tyler O'malley ${ }^{1}$, Kelley Brady ${ }^{1}$, Roberta Alexander ${ }^{1}$, Jing Shi ${ }^{1}$, Claudia Ibarra ${ }^{1}$, Michael Mahler ${ }^{2}$, Joel $\mathrm{Kremer}^{3}$, Michael E. Weinblatt ${ }^{4}$, Arthur Weinstein ${ }^{5} .{ }^{1}$ Exagen, Vista, United States of America; ${ }^{2}$ Inova Diagnostics, San Diego, United States of America; ${ }^{3}$ The Center for Rheumatology, Albany, United States of America; ${ }^{4}$ Brigham Women's Hospital, Boston, United States of America; ${ }^{5}$ Georgetown University, Washington D.C., United States of America

Background: Novel antibody systems including anti-Carbamylated Protein Antibody (anti-CarP $\operatorname{lgG}$ ) and anti-Peptidyl Arginine Deiminase Antibody (anti-PAD4 $\operatorname{lgG}$ ) are emerging as independent diagnostic and prognostic biomarkers for Rheumatoid Arthritis (RA) (ref, 1-3). As such, these antibody systems may add value to rheumatoid factor (IgM) and anti-citrullinated peptide antibody (ACPA IgG), the hallmark antibodies in RA.

Objectives: We evaluated the diagnostic performance of Rheumatoid Factor (RF) with antibody systems targeting citrullinated, carbamylated and PAD4 autoantigens in RA.

Methods: The cohort consisted of 638 consenting subjects with RA (fulfilling the 1987 or 2010 ACR classification criteria, mean age: $59.8 \pm 0.5$ years [SEM], $80 \%$ female) and a control group of 775 subjects (mean age: $44.7 \pm 0.5$ years, $85 \%$ females, including Systemic Lupus Erythematosus [ $\mathrm{n}=369]$, primary Sjogren's Syndrome $[\mathrm{n}=64]$, Primary Fibromyalgia [ $n=85$ ], other connective tissue diseases [ $\mathrm{n}=63]$, and a group of normal healthy donors $[n=194])$. Autoantibodies titers from serum were measured using fluoroenzyme immunoassays (anti-RF $[\mathrm{lgM}]$ and anti-CCP [lgG]; Phadia Upsala, Sweden), ELISA (anti-CarP [lgG], research use only [RUO], Inova Diagnostics, San Diego) and bead-based Aptiva ${ }^{\mathrm{TM}}$ technology (anti-PAD4 [lgG], RUO, Inova Diagnostics) in a clinical laboratory accredited by the College of American Pathologists. For each positive antibody (above each cutoff) a score of 1 was assigned and the cumulative presence of the 4 antibodies was determined [range 0-4]. The ability of the biomarkers to distinguish RA from controls was calculated using sensitivity, specificity and interval likelihood ratio (LR). Positive Predictive Value (PPV) was estimated at $10 \%$ pre-test probability. Statistics consisted of Mann-Whitney and Chi-square tests.

Results: In this cohort anti-CarP IgG ( $>20$ Units) yielded $33.5 \%$ sensitivity and $77.9 \%$ specificity. Anti-PAD4 (>1000 Units) yielded $35.0 \%$ sensitivity and $95.0 \%$ specificity. RF IgM ( $>5$ Units $/ \mathrm{ml}$ ) and anti-CCP (>10 Units $/ \mathrm{ml})$ were $67.4 \%$ and $66.5 \%$ sensitive, respectively $(87.5 \%$ and $97.0 \%$ specific, respectively). RA presented 5 -fold higher 4 -antibody system scores (2.02 $\pm 0.05)$ than controls $(0.42 \pm 0.02) ;(p<0.01)$. Scores greater than 2 yielded $42 \%$ sensitivity and $98.8 \%$ specificity. A total of 82 subjects presented with the full-house 4 antibodies (score $=4$ ) while 81 of them had RA (99.9\% specific). Interval LR and PV for each of the 4-antibody score are presented in the Table. There was no difference in the 4-antibody score between RA who fulfilled the 1987 ACR or 2010 ACR criteria $(1.99 \pm 0.07$ vs $2.08 \pm 0.09 ; p=0.40)$. In the subset of subjects newly diagnosed (less than one year), the average 4-antibody system score for RA $(n=33)$ was $1.72 \pm 0.22(36.3 \%$ with score greater than 2$)$ and $0.58 \pm 0.12$ for other diseases $(0 \%$ with score greater than $2, \quad 100 \%$ specific); $(\mathrm{p}<0.01)$.

Conclusion: This cumulative combination of antibody systems targeting citrullinated, carbamylated, PAD4 and Fc autoantigens (RF IgM) is highly specific for RA. It may be useful in diagnosing and classifying RA even in symptomatic patients who present early in the course of disease.

\section{REFERENCES}

[1] Shi, et al. Proc Natl Acad Sci USA. 2011 108(42):17372-7

[2] Darrah E et al. Sci Transl Med. 2013 2;5186ra65

[3] Verheul, et al. Arthritis Rheumatol. 2018 Nov;70(11):1721-1731
Table I: Combination of Rf IgM, anti-CCP (IgG), anti-CarP ( $\lg G)$ and anti-PAD4 $(\operatorname{lgG})$

\begin{tabular}{|c|c|c|c|c|c|c|}
\hline Score & RA $(\%, N)$ & $\begin{array}{l}\text { CTL }(\%, \\
\text { N) }\end{array}$ & $\begin{array}{l}\text { Likelihood } \\
\text { Ratio } \\
\text { [CI 95\%] }\end{array}$ & $\begin{array}{l}\text { Pre-test } \\
\text { Probability }\end{array}$ & $\begin{array}{l}\text { Post-test } \\
\text { Probability }\end{array}$ & Change \\
\hline 0 & $\begin{array}{c}20.5 \% \\
(131 / 638)\end{array}$ & $\begin{array}{c}65.8 \% \\
(510 / 775)\end{array}$ & $\begin{array}{c}0.31[0.27 \text { to } \\
0.37]\end{array}$ & $10 \%$ & $3.4 \%$ & $-6.6 \%$ \\
\hline 1 & $\begin{array}{c}11.6 \%(74 / \\
638)\end{array}$ & $\begin{array}{c}27.2 \% \\
(211 / 775)\end{array}$ & $\begin{array}{c}0.43[0.33 \text { to } \\
0.54]\end{array}$ & $10 \%$ & $4.5 \%$ & $-5.5 \%$ \\
\hline 2 & $\begin{array}{c}25.5 \% \\
(163 / 638)\end{array}$ & $\begin{array}{c}5.8 \%(45 / \\
775)\end{array}$ & $\begin{array}{c}4.40[3.22 \text { to } \\
6.02]\end{array}$ & $10 \%$ & $32.8 \%$ & $22.8 \%$ \\
\hline 3 & $\begin{array}{c}29.6 \% \\
(189 / 638)\end{array}$ & $\begin{array}{c}1.0 \%(8 / \\
775)\end{array}$ & $\begin{array}{c}28.70[14.26 \text { to } \\
57.77]\end{array}$ & $10 \%$ & $76.1 \%$ & $66.1 \%$ \\
\hline 4 & $\begin{array}{c}12.7 \%(81 / \\
638)\end{array}$ & $\begin{array}{c}0.1 \%(1 / \\
775)\end{array}$ & $\begin{array}{c}98.39[13.73 \text { to } \\
705.04]\end{array}$ & $10 \%$ & $91.6 \%$ & $81.6 \%$ \\
\hline
\end{tabular}

Disclosure of Interests: Thierry Dervieux Shareholder of: Exagen (a diagnostics company not a pharmaceutical company), Employee of: Exagen (a diagnostics company not a pharmaceutical company), John Conklin Employee of: Exagen (a diagnostics company not a pharmaceutical company), Tyler O'Malley Employee of: Exagen (a diagnostics company not a pharmaceutical company), Kelley Brady Employee of: Exagen (a diagnostics company not a pharmaceutical company), Roberta Alexander Employee of: Exagen (a diagnostics company not a pharmaceutical company), Jing Shi Employee of: Exagen (a diagnostics company not a pharmaceutical company), Claudia Ibarra Shareholder of: Exagen (a diagnostics company not a pharmaceutical company), Employee of: Exagen (a diagnostics company not a pharmaceutical company), Michael Mahler Employee of: Inova Diagnostics (Not pharmaceutical, diagnostics company), Joel Kremer Shareholder of: Corrona, Consultant for: AbbVie, Amgen, Bristol-Myers Squibb, Genentech, GSK, Lilly, Pfizer, Regeneron and Sanofi, Employee of: Corrona, Michael E. Weinblatt Shareholder of Stock option: CanFite, Lycera, Scipher, Inmedix, Grant/research support from: Crescendo Bioscience, Bristol Myers Squibb, Sanofi, Consultant for: AbbVie, Amgen, Bristol-Myers Squibb, CanFite, Corrona, Crescendo, GlaxoSmithKline, Gilead, Horizon, Lilly, Lycera, Merck, Novartis, Pfizer, Roche Samsung, Scipher, Set Point, Arthur Weinstein Shareholder of: Exagen (a diagnostics company not a pharmaceutical company), Consultant for: Exagen (a diagnostics company not a pharmaceutical company) DOI: 10.1136/annrheumdis-2019-eular.6351

\section{THU0072 ULTRASOUND PREDICTS IMMINENT PROGRESSION TO ARTHRITIS IN ANTI-CCP POSITIVE AT-RISK INDIVIDUALS}

Laurence Duquenne $^{1,2}$, Kulveer Mankia $^{1,2}$, Jacqueline Nam ${ }^{1,2}$, Peta Pentony ${ }^{1,2}$, Leticia Garcia-Montoya ${ }^{1,2}$, Andrea Dimatteo $^{1,2}$, Laura Hunt ${ }^{1,2}$, Paul Emery ${ }^{1,2}$.

${ }^{1}$ Leeds Institute of Rheumatic and Musculoskeletal Medicine, Leeds, United Kingdom; ${ }^{2}$ NIHR Leeds Biomedical Research Centre, Leeds, United Kingdom

Background: Ultrasound (US) Power Doppler (PD) signal is predictive for the development of inflammatory arthritis (IA) in anti-cyclic citrullinated protein antibodies positive (CCP+) individuals with musculoskeletal (MSK) symptoms but no clinical synovitis (CS) [1]. Our previous data showed a late increase in the overall US inflammation before arthritis development, suggesting that a sub-clinical phase of synovitis could be detected [2] This abstract describes the prediction of PD abnormalities in the months following US scan.

Objectives: 1 . Presence of PD in one joint is predictive of imminent progression to $I A$ in the next 3months.

2. A rise in the number of joints with presence of $P D$ increases the odds of progression to IA.

Methods: In a single-centre prospective observational cohort between June 2008 and December 2018, 307 CCP+ patients with a new MSK symptom but no synovitis were followed until CS occurred. Clinical and US findings were analysed. Following our previous study, we compared progression in the 3,12 or $>12$ months after a US scan. 38 joints were included in the analysis (MTPs, hands, wrists, elbows, ankles and knees). Patients with palindromic rheumatism were excluded.

Results: Data from $96 \mathrm{CCP}+$ at-risk patients who developed CS (progres sors) are compared to $211 \mathrm{CCP}+$ patients who did not (non-progressors) Age and gender are similar, the mean follow-up of the non-progressors is higher, with significantly more smokers and high titre CCP in the progressors group (Table1).

Overall, progressors have more joints with PD than non-progressors (Figure1). Patients with PD in one joint are more likely to develop CS in the following 3 months compared to those without PD (OR 7.52) and this remain significant when only the hands and wrists are included 